\title{
The Impact of Silver Nanoparticles Stabilized with Surfactant on Endothelial Cell Cycle Progression
}

\author{
Said Kaba ${ }^{1}$, Alice Sokolovskaya, Elena Egorova \\ Institute of General pathology and Pathophysiology \\ 8 Baltijskaya st, Moscow, 125315 Russia \\ 1said.kaba@niiopp.ru
}

\section{Extended Abstract}

Adverse effects of silver nanoparticles (AgNPs) on cultured cells include their impact on cell cycle progression. The influence of AgNPs on the known cell cycle phases - gap 1 (G1), synthetic (S) and gap 2 (G2) - allows detecting the initial stages of nanoparticle toxic effects preceding cell death, registered by cell viability decrease after treatment with AgNPs solutions. Considering the safety requirements for nanosilver applications in medicine, it is reasonable to clear out whether the effect of AgNPs on cell cycle exists at different nanoparticle concentrations found from cell viability measurements. In case if the nanoparticles are stabilized with surfactant, one should consider also the relevant biological properties of the stabilizer and its contribution to AgNPs cytotoxicity. The objective of this study was to assess the dose-dependent effect of silver nanoparticles stabilized with the surfactant aerosol-OT on cell cycle progression in endothelial cells. The AgNPs stock solution containing $1 \mathrm{mM}$ of silver nanoparticles and $1 \mathrm{mM}$ of aerosol-OT (AOT) was prepared by the original method of biochemical synthesis in aqueous medium [1]. The hydrodynamic size of particles was $38.11 \pm 0.76 \mathrm{~nm}$, with the zeta potential $-63.2 \pm 5.67 \mathrm{mV}$. Endothelial cells (Ea.hy926 line) [2] were incubated with AgNPs and AOT control solution for $24 \mathrm{~h}$. The stabilizer stock control solution was prepared with due regard for separate contributions of AOT monomers and micelles to the total AOT toxic effect [3]. Incubation with $1-7 \mu \mathrm{g} / \mathrm{mL}$ of AgNPs caused cell viability decrease as detected by tetrazolium salt (MTT) assay. The cytometric analysis of DNA content in cells treated with $1 \mathrm{and} 5 \mu \mathrm{g} / \mathrm{mL}$ AgNPs revealed the decrease of G1-phase (69 to 55\% of all counted cells) and the corresponding increase of S-phase (23 to $37 \%$ ). The both abovementioned changes, as well as accumulation of tetraploid cells, were dose-dependent. These data might indicate the complex impairment in cell proliferation, particularly cell cycle arrest at the DNA synthesis in treated cells. The results presented in this work can be useful in studies on the mechanism of nanoparticle cytotoxicity and draw attention to the possible adverse effects of surfactant-stabilized nanosilver.

\section{References}

[1] E. M. Egorova, A. A. Kubatiev, and V. I. Schvets, "Preparation of Metal Nanoparticles in Water Solutions on the Basis of Biochemical Synthesis," in Biological Effects of Metal Nanoparticles. Springer International Publishing Switzerland, 2016, pp. 125-147.

[2] J. Bauer, M. Margolis, C. Schreiner, C.-J. Edgell, J. Azizkhan, E. Lazarowski, and R. L. Juliano, "In vitro model of angiogenesis using a human endothelium-derived permanent cell line: contributions of induced gene expression, Gproteins, and integrins," J. Cell. Physiol., vol. 153, pp. 437-449, 1992.

[3] S. I. Kaba and E. M. Egorova, "The Contribution of Stabilizer to Silver Nanoparticle Cytotoxicity in Experiments on Endothelial and Fibroblast-Like Cells,” Nanotechnologies Russ., vol. 15, no. 4, pp. 507-515, 2020. 